\title{
Article \\ On the Use of Conformal Cooling in High-Pressure Die-Casting and Semisolid Casting
}

\author{
Anders E. W. Jarfors ${ }^{1, *(\mathbb{D}, \text { Ruslan Sevastopol }}{ }^{2}$, Karamchedu Seshendra ${ }^{2}$, Qing Zhang ${ }^{1}$, Jacob Steggo ${ }^{1}$ \\ and Roland Stolt ${ }^{3, *}$ \\ 1 School of Engineering, Materials and Manufacturing, Jönköping University, P.O. Box 1026, \\ 51111 Jönköping, Sweden; qing.zhang@ju.se (Q.Z.); jacob.steggo@ju.se (J.S.) \\ 2 Uddeholms AB, Uvedsvägen, 68385 Hagfors, Sweden; Ruslan.Sevastopolev@uddeholm.com (R.S.); \\ seshendra.karamchedu@uddeholm.com (K.S.) \\ 3 School of Engineering, Production and Design, Industrial Product Development, Jönköping University, \\ P.O. Box 1026, 51111 Jönköping, Sweden \\ * Correspondence: anders.jarfors@ju.se (A.E.W.J.); roland.stolt@ju.se (R.S.)
}

check for updates

Citation: Jarfors, A.E.W.; Sevastopol, R.; Seshendra, K.; Zhang, Q.; Steggo, J.; Stolt, R. On the Use of Conformal Cooling in High-Pressure Die-Casting and Semisolid Casting. Technologies 2021, 9, 39. https://doi.org/10.3390/ technologies 9020039

Academic Editor: Erhan Budak

Received: 21 April 2021

Accepted: 18 May 2021

Published: 21 May 2021

Publisher's Note: MDPI stays neutral with regard to jurisdictional claims in published maps and institutional affiliations.

Copyright: (c) 2021 by the authors. Licensee MDPI, Basel, Switzerland. This article is an open access article distributed under the terms and conditions of the Creative Commons Attribution (CC BY) license (https:// creativecommons.org/licenses/by/ $4.0 /)$.

\begin{abstract}
Today, tool life in high pressure die casting (HPDC) is of growing interest. A common agreement is that die life is primarily decided by the thermal load and temperature gradients in the die materials. Conformal cooling with the growth of additive manufacturing has raised interest as a means of extending die life. In the current paper, conformal cooling channels' performance and effect on the thermal cycle in high-pressure die casting and rheocasting are investigated for conventional HPDC and semisolid processing. It was found that conformal cooling aids die temperature reduction, and the use of die spray may be reduced and support the die-life extension. For the die filling, the increased temperature was possibly counterproductive. Instead, it was found that the main focus for conformal cooling should be focused to manage temperature around the in-let bushing and possibly the runner system. Due to the possible higher inlet pressures for semisolid casting, particular benefits could be seen.
\end{abstract}

Keywords: additive manufacturing; conformal cooling; high pressure die casting; tooling; semisolid casting; heat flux; solidification; casting; component

\section{Introduction}

Currently, there is a strong focus on tool life in high pressure die casting (HPDC). Die life is primarily decided by the thermal load and temperature gradients in the die materials. Sivertsen [1] concluded that die life prediction based on thermal stress could be used to predict the failure's location and that the gate area was common for a part cast using AlMg5Si2Mn. The stresses arise as a consequence of thermal load. AlMg5Si2Mn is a material commonly causing die soldering, and die spray is commonly used to keep the temperature below the critical temperature for soldering, adding to the stresses, lowering die life further. Sivertsen [1] also concluded that mould erosion was very predictable and directly related to the die design and could be minimized using process parameters targeting a low local fill speed. The most crucial process parameter to achieve longer die life was the tempering channels based on the assumption that effective heat removal promotes long die life.

In tooling, the first choice is that of the material, and the correct choice depends on the thermal load and series size [2]. Different die materials have different thermal transport properties that will affect material performance significantly [3]. In an effort to extend die life, reinforcements have been tested but with limited success [4]. Armilotta et al. [5] have shown more promising results that designed a conformal cooling system for HPDC casting with a number of different advantages. In contrast to injection moulding, where cycle time and shrinkage defects were significantly reduced, the benefits were very different 
for HPDC casting. The increased cooling rate reduced the necessary amount of lubricant sprayed on die surfaces. The amount of shrinkage porosity was also reduced, confirming that the part quality will be improved when managing the cooling channels correctly. In a study of the lifespan of a mould insert, Fiorentini et al. [5] found that the effective cooling of a core insert significantly improved its life, confirming the findings by Sivertsen [1]. Fiorentini et al. [5] further concluded that the fast cooling observed with the conformal cooling channels increases productivity. Critically analyzing this statement reveals that not only is the temperature lower, but also the actual cooling rate is increased. This is advantageous from a solidification perspective but not from a filling perspective. It should be assumed that conformal cooling should require an increased fill speed, especially in thinner wall sections, meaning more turbulence and reduced part quality. This assumption then indicates that there are issues related to conformal cooling channel design and, in particular, the distance to the insert surface and direction of flow.

Arisuda et al. [6] studied the effect of injection speed on the die life. They concluded that wide crack occurred for both high and low injection speed. The growth of runner cracks depended on both a significant high-temperature-induced softening and the stresses occurring due to flow and solidification. A higher injection speed resulted in lower dielife and faster crack growth in the long run, even though a lower injection speed caused significantly increased cracking. Controlling the initial thermal shock is one element of control, and the other is to prevent tool softening. The initial heat flux in HPDC processing is very high and a different problem compared to that associated with the overall temperature control of the material. Cao et al. [7] investigated the heat flux and interfacial heat transfer coefficients with the initial maximum values in the range of $5.8-9.2 \mathrm{MW} / \mathrm{m}^{2}$ for the heat flux and with heat transfer coefficients in the order of $17-64 \mathrm{~kW} / \mathrm{m}^{2} \mathrm{~K}$ depending on location in the die. This implies that the temperature drop across the interphase initially is in the range of $140-340^{\circ} \mathrm{C}$. This is under the assumption that there is no solid phase in the material. The presence of a solid phase, such as in semisolid casting, may reduce the interfacial heat transfer coefficient by a factor of 2, depending on solid fraction and actual interface temperature [8]. Since the thermal conductivity is higher in the melt than in the steel mould, most of the temperature change will end up in the steel die. With a liquidus temperature in the melt commonly in the range of $570-620^{\circ} \mathrm{C}$, the initial contact will also be in this range, assuming that most of the superheat is lost in handling and the shot sleeve. This suggests that the minimum temperature would be in the order of $230^{\circ} \mathrm{C}$ but could be as high as $480{ }^{\circ} \mathrm{C}$ in some parts of the die cavity based on heat transfer, including the die spray effect as included in the study by Cao et al. [7].

Following the analysis of Long et al. [9], understanding the temperature at the interface can be made through the Riemann temperature, $T_{R}$, that is an estimate of the interface temperature excluding die spray and only focusing on the die and cast metal properties

$$
T_{R}=\frac{\beta_{1} T_{1}+\beta_{2} T_{2}}{\beta_{1}+\beta_{2}}
$$

where $T_{1}$ is the melt temperature; $T_{2}$ is the die temperature; and $\beta$ is the cooling capacity of the material defined as $\beta_{i}=\sqrt{\lambda_{i} \rho_{i} C_{P}^{i}}$ with $\lambda_{i}$, thermal conductivity of material I; $\rho_{i}$, density of material $i$; and $C_{P}^{i}$, specific heat of material $i$. Keeping both metal and tool material temperatures down will reduce the contact temperature as the Riemann temperature. The same is valid for a high-density mould material with a large specific heat and high thermal conductivity. The Riemann temperature for a typical die casting situation would be $344^{\circ} \mathrm{C}$. With the suggested temperature drops over the interface, the cast aluminium alloy's surface temperature would be close to its melting temperature. The metal temperature would not surpass this temperature with an additional thermal resistance at the interface. This also means that there is a direct relationship between the core tooling temperature with its maximum surface temperature based on Equation (1) that during die spray will cause tensile stress. 
The design of the cooling channels is the next element to consider. Additive manufacturing gives great freedom in the design, but there are challenges to achieving a high-quality die that meets the required tolerances, and there will be parts that need machining that indirectly may put restrictions on the design [10]. The channels may offer two different types of cooling qualities. One is general heat transport to another region in the die or outside the die. The conventional mode of operation is to remove heat, meaning heat transport to a location outside the die. Concurrently this function should support die filling and solidification and is, as such, not independent of casting design. The conformal cooling mode significantly impacted the polymer industry in polymer injection moulding targeted to affect the actual part being formed. To affect this, the distance to the surface is related to cycle time through the Einstein relation [11]. An advancing heat pulse will reach a certain depth in a specific time. Since most die cavities are essentially flat, a one-dimensional estimate is sufficient where the depth, $d$, is related to time, $t$, as

$$
d=\sqrt{2 \frac{\lambda t}{\rho C_{P}}}
$$

Here $\lambda$ is thermal conductivity, $C_{p}$ is specific heat, and $\rho$ is density. This means that for the channel to significantly react during the filling process that typically takes 30-70 ms., the maximum depth is in the order of $1 \mathrm{~mm}$. Similarly, for the channel to affect the solidification of the part that typically takes $5 \mathrm{~s}$ and 10-20 s for the biscuit, the depth requirements are $9 \mathrm{~mm}$ in the part cavity region and 13-19 $\mathrm{mm}$ in the biscuit region. This suggests that some effect can be practically achieved in the part. However, the effects in the runner and biscuit region can be significant as $5-10 \mathrm{~mm}$ below the surface appears reasonable for a $10-\mathrm{mm}$ channel in the biscuit area and $2.5-5 \mathrm{~mm}$ for a $5-\mathrm{mm}$ channel in the part region following design recommendations from the polymer injection moulding die design [12]. If only general thermal control is sought, then the design criteria for the channel to affect the part over the production cycle duration, $t_{c y c l e}$, then becomes

$$
d_{\text {crit }}<\sqrt{2 \frac{\lambda t_{\text {cycle }}}{\rho C_{P}}}
$$

The immediate conclusion is that general temperature control is immediately feasible and that reducing temperatures in the biscuit and gating region is well within reach while the control of solidification is outside the reach, other than controlling temperature in general. In general, this general temperature control is also beneficial as the amount of die spray is reduced [11].

The relationship between cooling rate, $\frac{d T}{d t}$, and microstructure is best viewed through the secondary dendrite arm spacing or SDAS that for the current ally can be described as [13]

$$
S D A S=50 \cdot 10^{-6}\left(\frac{d T}{d t}\right)^{-0.33}
$$

In the current paper, the performance and effect of conformal cooling channels on the thermal cycle in high-pressure die casting and rheocasting are investigated.

\section{Materials and Methods}

2.1. Experimental Set-up

2.1.1. Casting System

A 50-ton vertical high pressure die casting system was used with a die set casting a tensile bar. The system was equipped with a RheoMetal [14] manual slurry-making system for the semisolid casting trials. The reason for both casting in a conventional molten mode and a semisolid mode is that the heat transfer coefficient for semisolid casting is significantly lower than for conventional casting, thus possibly influencing the temperature distribution in the die material [7]. 
The temperature of the melt was measured using a K-type thermocouple. The melt was manually ladled from the furnace to the shot sleeve using a single-stage short profile to accommodate both molten and semisolid casting. The single-stage piston speed was $0.1 \mathrm{~m} / \mathrm{s}$, and the intensification pressure was 175 bar. The dwell time in the die was set to $18 \mathrm{~s}$, resulting in a total cycle time of approximately $45 \mathrm{~s}$ with manual extraction of the sample.

The typical temperature of the pressurized oil cooling was $178^{\circ} \mathrm{C}$. During the casting experiments, temperature measurements were performed on the surface of the insert using a thermal imaging camera, and the temperature and flow of the oil (coolant) was also recorded.

The material cast was EN-AC 42,000 material with a composition shown in Table 1. After replenishing the melt on day 1, the Si content was slightly low but not significant for the current analysis purpose. Ti additions usually are not regarded as required for HPDC processing and only relevant for gravity die casting, which is the common use of EN-AC 42,000. In the first set of experiments using a conventional die set, 28 samples were produced with the fully molten were cast first (13 pcs.) followed by semisolid cast samples (15 pcs.).

Table 1. Alloy specification and the three different compositional samples taken from the material produced.

\begin{tabular}{ccccccccccc}
\hline Material & $\mathbf{C u}$ & $\mathbf{F e}$ & $\mathbf{M g}$ & $\mathbf{M n}$ & $\mathbf{P b}$ & $\mathbf{S i}$ & $\mathbf{T i}$ & $\mathbf{Z n}$ & $\mathbf{A l}$ \\
\hline EN-AC42000 & $\leq 0.20$ & $\leq 0.55$ & $0.20-0.65$ & $\leq 0.35$ & $\leq 0.15$ & $6.5-7.5$ & $0.05-0.25$ & $\leq 0.15$ & bal. \\
Day 1 Melt 1 & 0.052 & 0.34 & 0.53 & 0.20 & 0.010 & 6.66 & 0.034 & 0.084 & bal. \\
Day 1 Melt 2 & 0.050 & 0.32 & 0.51 & 0.19 & 0.009 & 6.27 & 0.036 & 0.080 & bal. \\
Day 2 Melt 3 & 0.052 & 0.34 & 0.55 & 0.20 & 0.012 & 6.75 & 0.036 & 0.11 & bal. \\
\hline
\end{tabular}

The second set of experiments was made using a conformal cooling die. The set-point of the oil was required to be increased to fill the die. Here, a total of 24 samples were cast, with the fully molten samples being cast first (16 pcs.) followed by the semisolid cast material (8 pcs).

\subsubsection{Tooling and Tooling Design}

Two different inserts were used, one equipped with a conformal cooling system and one without this cooling channel, Figure 1. The tooling material composition and characteristics are shown in Table 2. The parameters for printing the tool steel powder, using an EOS M290 PBF-LB/M system, were:

- $\quad$ Layer Height $=40 \mu \mathrm{m}$

- Laser Power $=296 \mathrm{~W}$

- $\quad$ Scan speed $=790 \mathrm{~mm} / \mathrm{s}$

- $\quad$ Hatch Distance $=0.126 \mathrm{~mm}$

- $\quad$ Stripe width $=9.75 \mathrm{~mm}$

- Overlap $=0.12 \mathrm{~mm}$

Table 2. Chemical composition and characteristics of the additive material used for the inserts.

\begin{tabular}{ccccccccc}
\hline C & Si & Mn & Cr & Mo & Co & Cu & Ni & O \\
\hline 0.03 & 0.35 & 0.40 & 5.0 & 8.0 & 12.0 & 2.0 & 2.0 & $<250$ ppm \\
\hline $\begin{array}{c}\text { D10 } \\
(\mu \mathrm{m})\end{array}$ & $\begin{array}{c}\text { D50 } \\
(\mu \mathrm{m})\end{array}$ & $\begin{array}{c}\text { D90 } \\
(\mu \mathrm{m})\end{array}$ & Sphericity & Aspect Ratio & $\begin{array}{c}\text { True Density } \\
\left(\mathbf{g} / \mathrm{cm}^{3}\right)\end{array}$ & $\begin{array}{c}\text { Tap Density } \\
\left(\mathbf{g} / \mathrm{cm}^{3}\right)\end{array}$ \\
\hline 0.03 & 0.35 & 0.40 & 0.93 & 0.9 & 8.0 & 2.0 \\
\hline
\end{tabular}



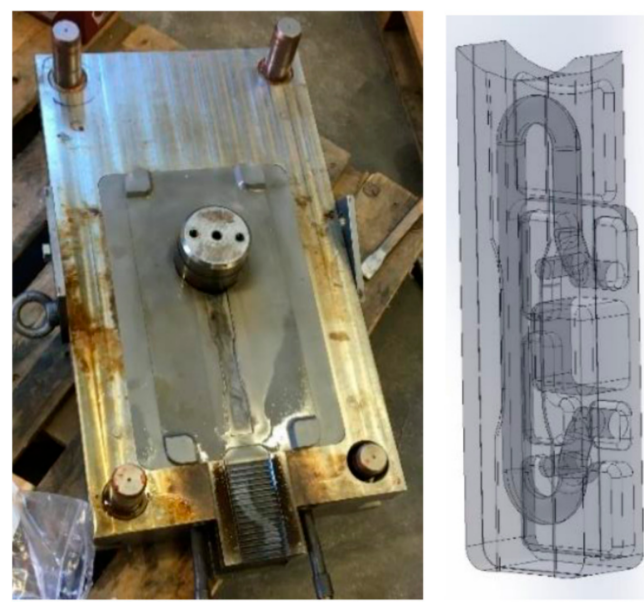

(a)
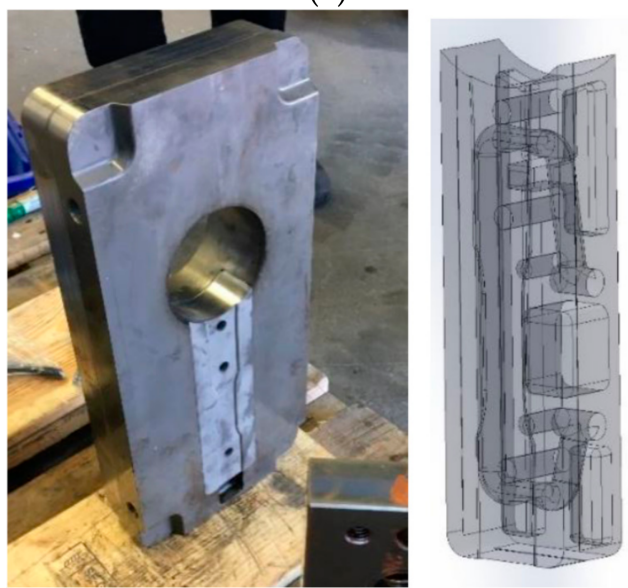

(b)

Figure 1. Conformal die (a) fixed die insert, (b) ejector die insert.

The printed insert was heat-treated to relieve stresses introduced by the printing process and to get the desired tool insert microstructure and properties. The heat treatment was performed under a vacuum. The base plate with the printed inserts was heated up to the solution treatment/stress reliving temperature of $950^{\circ} \mathrm{C}$ and held for $1 \mathrm{~h}$. Cooling to room temperature was made under controlled conditions with the cooling time between $800{ }^{\circ} \mathrm{C}$ and $500{ }^{\circ} \mathrm{C}$ managed to $100 \mathrm{~s}$. After heat treatment, the tooling was machined to tolerance in the final design.

The channel diameter was $10 \mathrm{~mm}$. The distance from the top surface was $10 \mathrm{~mm}$. It suggested that filling should be relatively unaffected by the channel itself and that the distance could affect solidification but mainly targeting tool temperature homogenization and the cooling cycle that would also affect spraying.

\subsubsection{Die Temperature Assessment}

Die temperatures were measured using a thermal imaging camera FLIR T640 with a temperature range of $-40-2000{ }^{\circ} \mathrm{C}$ with an accuracy of $\pm 2{ }^{\circ} \mathrm{C}$ or $2 \%$. The printed steel emissivity was approximated to 0.78 , but this will not stay constant in a foundry environment with die spray being used and should be seen as an approximation. This setup allowed for quantitative imaging and post-processing to assess temperature distribution in points or along a line in the die cavity. Similarly, it was possible to assess the time evolution at a specific point for a quantitative assessment of the cooling rates. 


\section{Results and Discussion}

The casting was made in two different modes with and without conformal cooling and semisolid and conventional fully molten high pressure die casting mode. This also means that heat input and cooling mode varied.

\subsection{Part Cooling Capacity Difference}

The difference between the cooling capacity between the conformal cooling die and the conventional die is determined through the differences between the change in oil temperature for the two different inserts and a relative assessment of the in-die cooling rate through measurement of the oil flow rate and change during a shot, using the fully molten state to ensure a constant heat flux on part injection.

Doing a heat balance to assess the relative change in the cooling rate in the die cavity based on a system-level can be done in the following way.

The heat balance in the system consists of two sources

1. Change of heat flux in the die, related to the part solidification, $\left(\frac{d Q}{d t}\right)_{D}$

2. Change of heat flux in the rest of the system's outer die surface, hoses, and other die assembly components, $\left(\frac{d Q}{d t}\right)_{L}$

$$
\frac{d Q}{d t}=\left(\frac{d Q}{d t}\right)_{D}+\left(\frac{d Q}{d t}\right)_{L}
$$

The change in the die is

$$
\left(\frac{d Q}{d t}\right)_{D}=m_{M} C_{p}^{M} \frac{d T_{M}}{d t}
$$

where $m_{M}$ is the mass of metal, $C_{p}^{M}$ is the specific heat of the metals, $T_{M}$ is the metal temperature, and $t$ is time. The change in the external loop/rest of the system is

$$
\left(\frac{d Q}{d t}\right)_{L}=m_{O} C_{p}^{O} \frac{d T_{O}}{d t} \approx v_{O} \rho_{O} C_{p}^{O}\left(T_{O}^{o u t}-T_{O}^{i n}\right)
$$

where $m_{O}$ is the mass of oil, $C_{p}^{O}$ is the specific heat of the oil, $T_{O}$ is the metal temperature, $v_{O}$ is the volumetric flow of the oil, $\rho_{O}$ is the oil density, and $T_{O}^{o u t}-T_{O}^{i n}$ is the temperature difference between the outgoing oil and the incoming oil. In order to do the engineering estimate of the cooling channel design, efficiency assumptions are required

Assumptions

1. Before the shot, there is no cooling of metal inside, meaning that $m_{M}=0$

2. The heat extraction of the system is over a short time, such as the duration of the filling and solidification; constant meaning that

$$
\frac{d Q}{d t}=\text { const }
$$

This allows us to take the difference after the shot $\left(\frac{d Q}{d t}\right)_{A}$ and subtract the conditions before the shot $\left(\frac{d Q}{d t}\right)_{B}$ as

$$
\begin{aligned}
& \left(\frac{d Q}{d t}\right)_{A}=\left(\frac{d Q}{d t}\right)_{D, A}+\left(\frac{d Q}{d t}\right)_{L, A} \\
& \left(\frac{d Q}{d t}\right)_{B}=\left(\frac{d Q}{d t}\right)_{D, B}+\left(\frac{d Q}{d t}\right)_{L, B}
\end{aligned}
$$


Combining Equation (9) and (10) with the assumption (8) means that

$$
\left(\frac{d Q}{d t}\right)_{A}-\left(\frac{d Q}{d t}\right)_{B}=\left(\frac{d Q}{d t}\right)_{D, A}+\left(\frac{d Q}{d t}\right)_{L, A}-\left(\frac{d Q}{d t}\right)_{D, B}-\left(\frac{d Q}{d t}\right)_{L, B}=0
$$

The expressions for the individual terms in Equation (11) will then be:

$$
\begin{gathered}
\left(\frac{d Q}{d t}\right)_{D, A}=m_{M} C_{p}^{M} \frac{d T_{M}}{d t} \\
\left(\frac{d Q}{d t}\right)_{L, A} \approx v_{O} \rho_{O} C_{p}^{O}\left(T_{O}^{o u t, A}-T_{O}^{i n, A}\right) \\
\left(\frac{d Q}{d t}\right)_{D, B}=m_{M} C_{p}^{M} \frac{d T_{M}}{d t} \equiv 0 \\
\left(\frac{d Q}{d t}\right)_{L, B} \approx v_{O} \rho_{O} C_{p}^{O}\left(T_{O}^{o u t, B}-T_{O}^{i n, B}\right)
\end{gathered}
$$

Rearranging Equation (11) gives

$$
\left(\frac{d Q}{d t}\right)_{D, A}=\left(\frac{d Q}{d t}\right)_{D, B}+\left(\frac{d Q}{d t}\right)_{L, B}-\left(\frac{d Q}{d t}\right)_{L, A}=\left(\frac{d Q}{d t}\right)_{L, B}-\left(\frac{d Q}{d t}\right)_{L, A}
$$

And inserting Equations (11)-(15) into (16) gives

$$
m_{M} C_{p}^{M} \frac{d T_{M}}{d t}=v_{O} \rho_{O} C_{p}^{O}\left(\left(T_{O}^{o u t, B}-T_{O}^{i n, B}\right)-\left(T_{O}^{o u t, A}-T_{O}^{i n, A}\right)\right)
$$

To compare the conformal cooling and the non-conformal cooling in terms of the cooling rates in the die, the easiest way is to take the ratio of the conformal cooling conditions to the conventional cooling conditions, making use of the fact that the mass of metal in the die was unchanged shows that.

$$
\begin{aligned}
& \frac{\frac{d T_{M}}{d t} \text { Conformal }}{\frac{d T_{M}}{d t} \text { Conventional }} \\
& =\frac{\left(v_{O}^{\text {Conformal }} \rho_{O} C_{p}^{O}\left(\left(T_{O}^{\text {out }, B}-T_{O}^{\text {in }, B}\right)-\left(T_{O}^{\text {out }, A}-T_{O}^{\text {in }, A}\right)\right)\right)_{\text {Conformal }}}{\left(v_{0}^{\text {Conventional }} \rho_{O} C_{p}^{0}\left(\left(T_{0}^{\text {out }, B}-T_{O}^{\text {in }, B}\right)-\left(T_{O}^{\text {out }, A}-T_{O}^{\text {in }, A}\right)\right)\right)_{\text {Conventional }}}
\end{aligned}
$$

During the casting cycle, there is no change of the oil coming into the die and the die tempering oil coming into the die; $T_{O}^{\text {in }}$ does not change before and after. Equation (18) can be simplified as:

$$
\frac{\frac{d T_{M}}{d t} \text { Conformal }}{\frac{d T_{M}}{d t} \text { Conventional }}=\frac{\left(v_{O}^{\text {Conformal }} \rho_{O} C_{p}^{O}\left(\left(T_{O}^{\text {out }, B}-T_{O}^{\text {out }, A}\right)\right)\right)_{\text {Conformal }}}{\left(v_{O}^{\text {Conventional }} \rho_{O} C_{p}^{O}\left(\left(T_{O}^{\text {out }, B}-T_{O}^{\text {out }, A}\right)\right)\right)_{\text {Conventional }}}
$$

During the experiments with fully molten material, the temperature change of oil during the casting cycle with conformal die inserts was $1.84{ }^{\circ} \mathrm{C}$ with an oil flow rate of $13.1 \mathrm{~L} / \mathrm{min}$. For the conventional die, the corresponding values were a temperature change of $0.41^{\circ} \mathrm{C}$ with an oil flow rate of $19.3 \mathrm{~L} / \mathrm{min}$. This suggests that the overall cooling capacity of the specimen using the die inserts with conformal cooling was three times higher than for the conventional die insert. A higher cooling efficiency was expected, which was also confirmed through the heat balance of the oil tempering system. Due to the masses in the system, including the hole tooling and machine, this number should be seen as a lower bound estimate of the change in cooling rate, as there is a significant dampening of the 
thermal signal. Thus, there is a potential reduction to $70 \%$ of the secondary dendrite arm spacing, as proposed by Equation (4), which may affect defect size and distribution but provides a minor effect on mechanical properties, provided that the occurrence of filling defects is significantly affected.

\subsection{Cooling Rates}

The increased cooling capacity will also change the cooling rates for the two different die inserts and affect the metal differently, provided that it is semisolid or fully molten. The interfacial heat transfer coefficient usually is lower in the semisolid state, reducing the surface temperature of the die inserts and the total heat input reduced as some heat of fusion was removed outside of the die.

After the part ejection, the cooling rate, as shown in Figure 2a,b, was measured at a point located in the middle of the gauge section, Figure 2c. The location is shown as the red dot in the schematic drawing of the upper moving die half. For both conformal cooling curves, there is a clear difference compared to the conventional die inserts. The initial drop in temperature for the conformal cooling die is significantly more rapid than for the conventional die, Figure $2 \mathrm{a}$. The first $0.5 \mathrm{~s}$ of this cooling is shown in Figure $2 \mathrm{~b}$, where a power-based trendline was also fitted to calculate the cooling rate.

After the initial $0.2 \mathrm{~s}$ initial transient, the conditions were visible. Firstly, the semisolid cast material temperature was significantly lower than that of the conventionally cast material. This confirms that the reduced heat input into the die also results in a reduced die temperature. Secondly, for both cases, the conformal die temperature was below that of the conventional die design, supporting the literature claims of a reduced need for spray cooling using conformal cooling as die temperature was reduced for aluminium alloy casting [11].

Comparing the cooling rates for the first $0.5 \mathrm{~s}$ and taking the average ratio showed that the cooling rate for the molten case resulted in the cooling rate of the conformal cooling die being 8 times faster than the conventional die. There was no significant difference between the conformal and conventional die for the semisolid cast, suggesting that the heat transfer rate was primarily controlled through the interfacial heat transfer coefficient, keeping the temperature down. The ratio was approximately 1.

Comparing the casting method's effect from a fully molten process to a semisolid process for the two different cases also gives an interesting picture. The conventional die's cooling rate was 10 times faster for the semisolid casting than for the fully molten sample, indicating significant heat retention in the die material casting fully molten metal. This supports the idea that the subsurface temperature and heat accumulation, due to specific heat and subsurface temperature distribution, are important for the initial stage cooling. Comparing the two casting processes for the conformal cooling system shows similar cooling rates, again with an approximate ratio of 1 .

\subsection{Temperature Distribution}

Typical temperature distributions are shown in Figure 3a-d directly after part ejection. It should be noted that the scale is different in the images to display the variations for the different cases. The brightest hot region was in the inlet and biscuit region, which are usually the hottest regions in a die. The conformal cooling channels are not clearly visible, suggesting that the metal heating is dominant for the temperature distribution. In Figure $3 d$, some hotter regions may be visible along the die cavity on the left-hand side, which may be the conformal channel showing. 


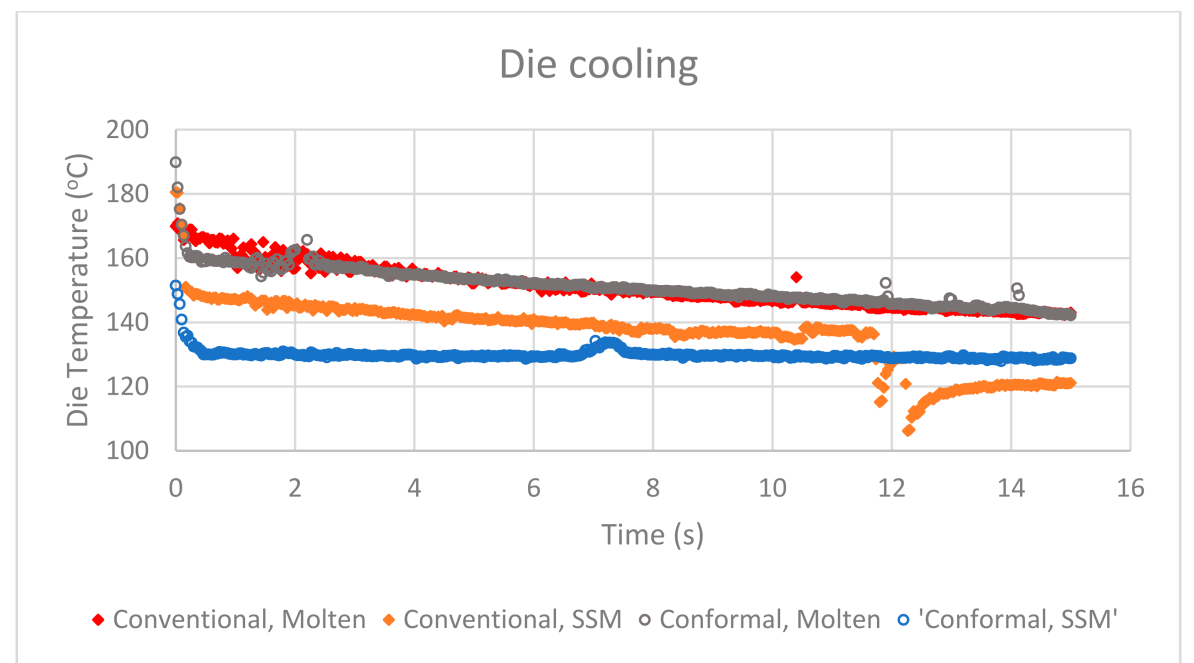

(a)

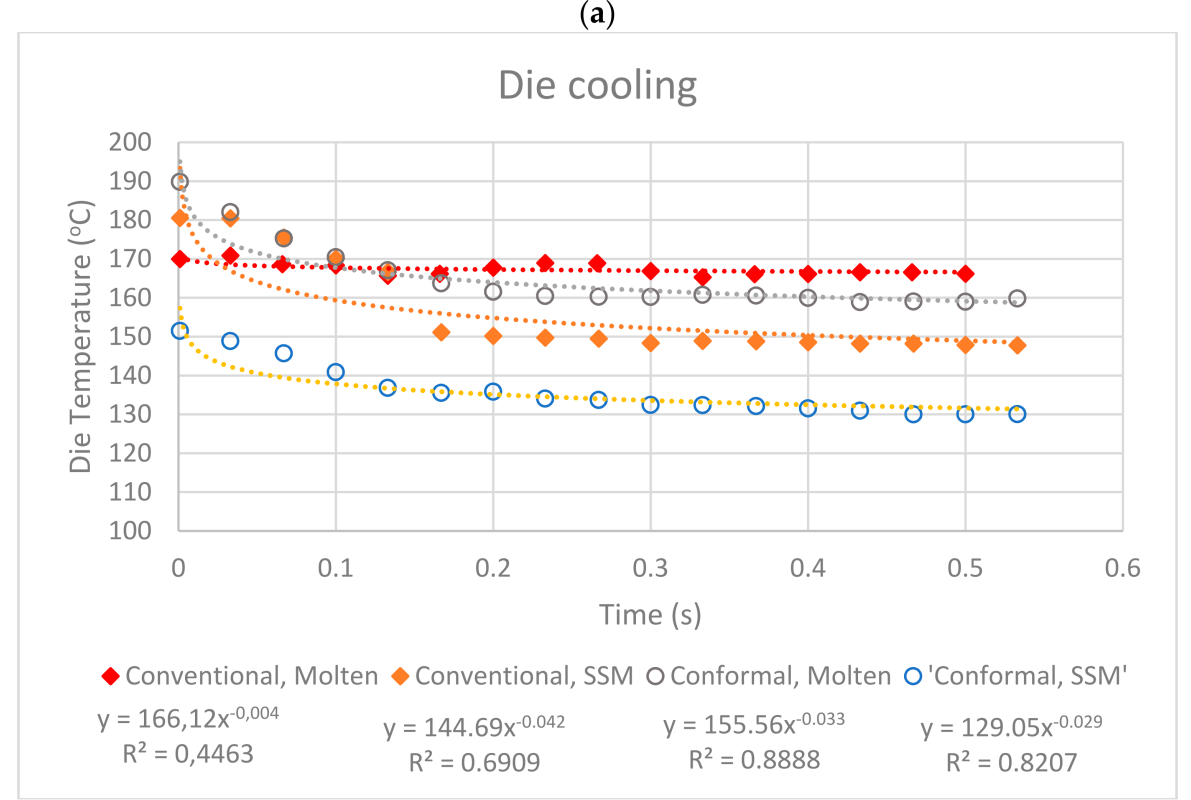

(b)

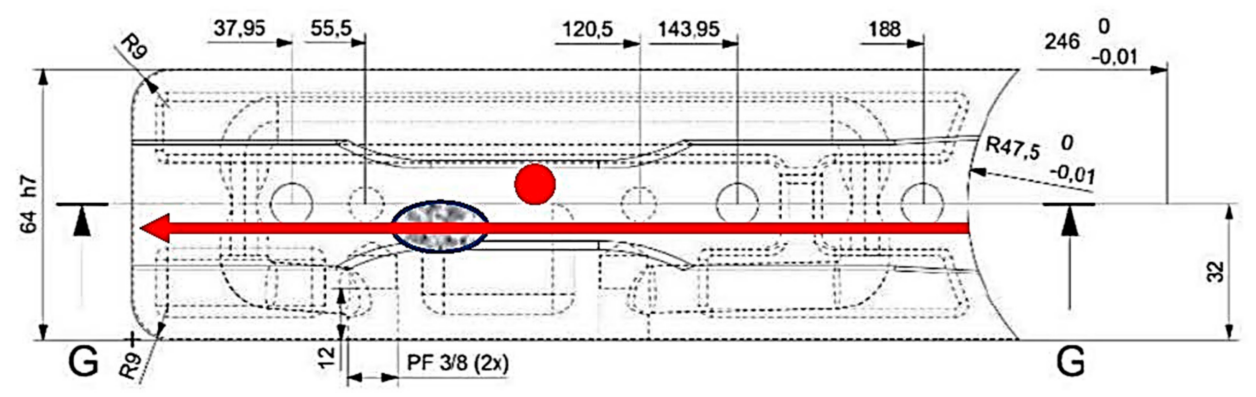

(c)

Figure 2. Die cooling illustration with (a) the overall cooling for the four different combinations of conformal cooling, conventional cooling, high pressure die casting (molten), and rheocasting (SSM); (b) details of the initial $0.5 \mathrm{~s}$ cooling with trendlines to allow an estimation of the cooling rates through the derivative of the cooling rate; and (c) the location of the cooling curve assessment (the red point) and the line for assessment of temperature homogeneity with the arrow indicating filling direction. The grey area is an area of particular interest that is discussed below. 
To quantify the temperature distribution, the temperature along the line shown in Figure $2 c$ was evaluated for the four different cases, Figure $4 a-d$. There is a waviness in the curves that arises from the measurements as the ejector pins in the protruding position carry heat reflected in the surface, adding to the radiation. These reflections of the ejector pins are also seen in Figure $3 \mathrm{a}-\mathrm{d}$. There is also a minor uncertainty in the starting and endpoints as these had to be estimated since the camera was not in a fixed position and it had to be moved for die disassembly to change inserts.

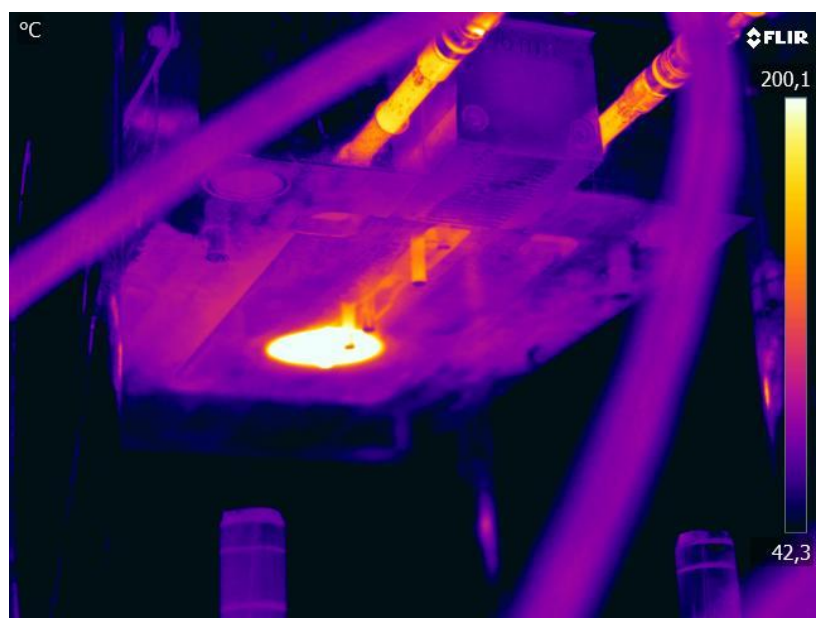

(a)

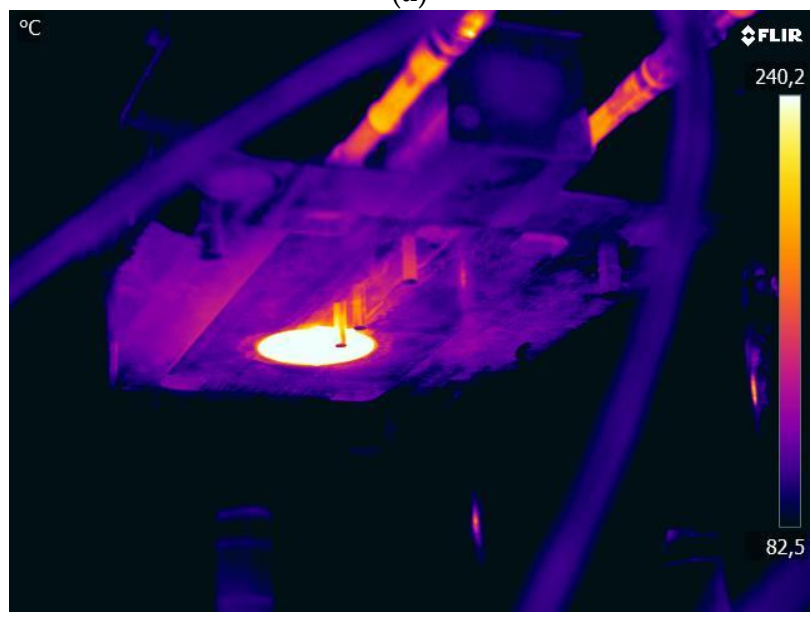

(b)

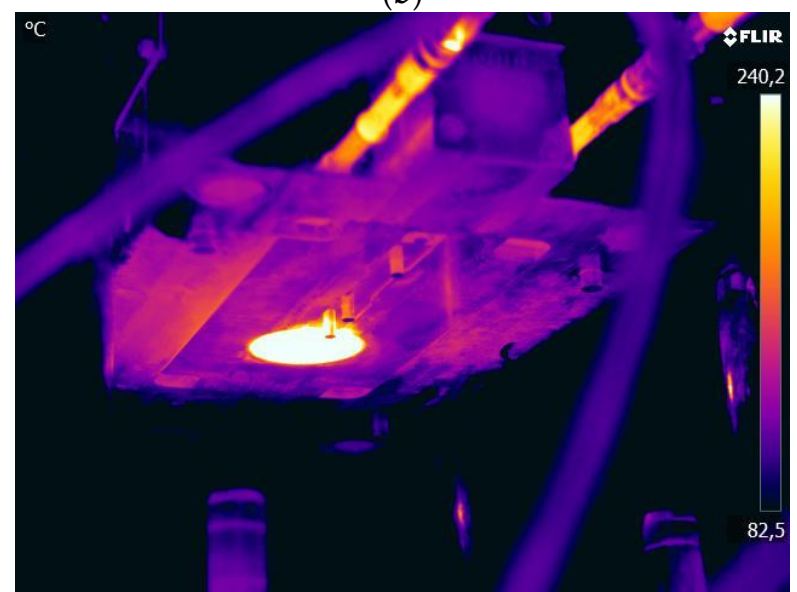

(c)

Figure 3. Cont. 


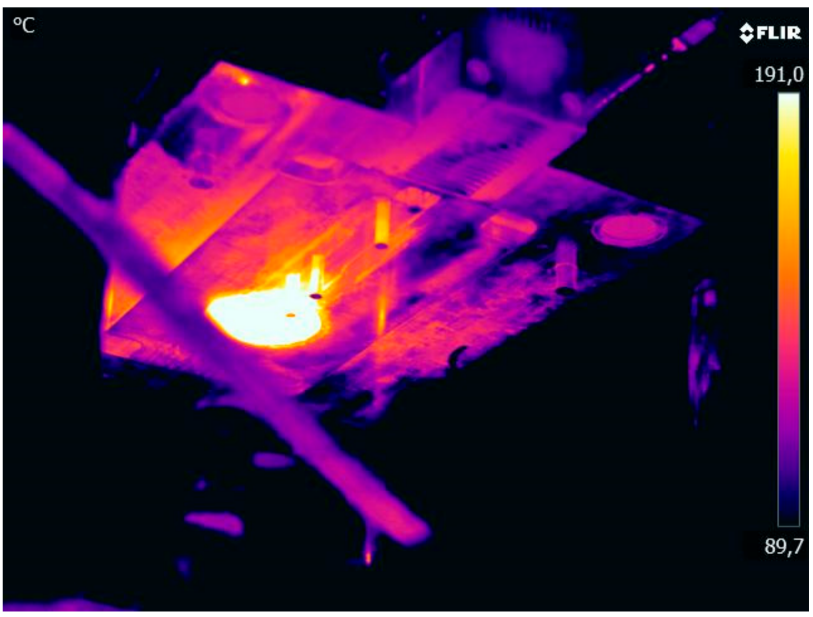

(d)

Figure 3. Illustration of temperature distributions in the upper moving die surface for (a) conventional die and a fully molten material; (b) conventional die with semisolid casting; (c) conformal die and a fully molten casting, and (d) conformal cooling and semisolid casting.

To create a comparison between the cases, an exponential function was fitted for each shot, and the absolute value of the fitted slope was evaluated for every $5 \mathrm{~mm}$ along the insert. The average value was taken for each test condition. The outcome is shown in Figure 5a, where it can be seen that the lowest temperature gradient was found for a fully molten casting in a conventional die insert. Reducing the heat input by changing to a semisolid casting increased the gradient somewhat, and this curve is seemingly overlapping that of the fully molten casting with conformal cooling. A possible reason for this is that because of an increased cooling capacity, as indicated by Equation (19) and supported by the post ejection cooling rate from the discussion in Figure $2 b$, the material's temperature loss is high for the fully molten material in the conformal cooling die.

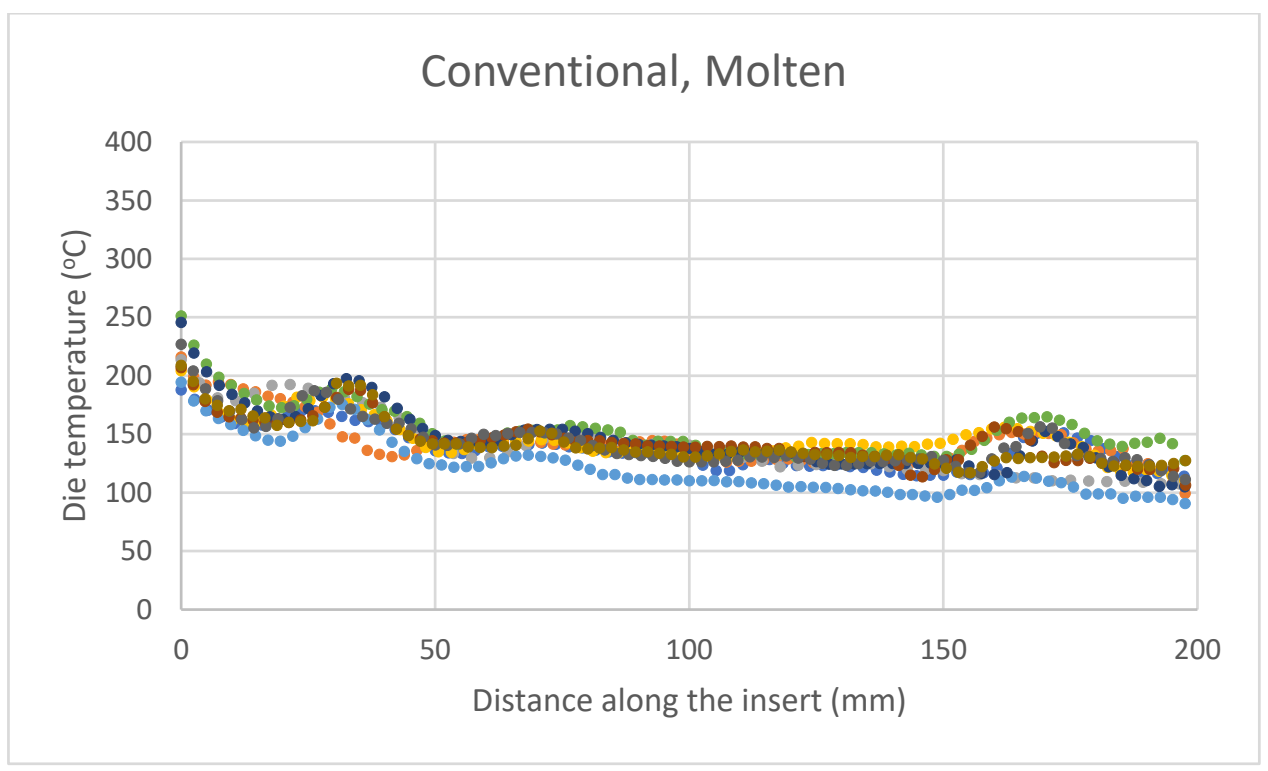

(a)

Figure 4. Cont. 


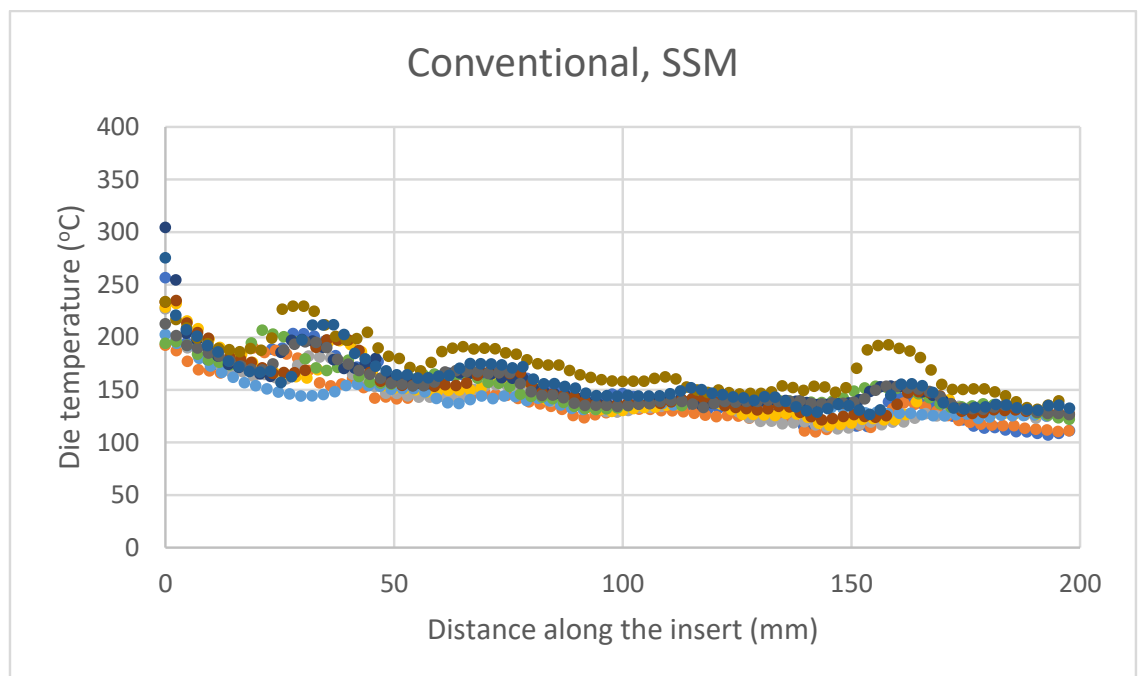

(b)

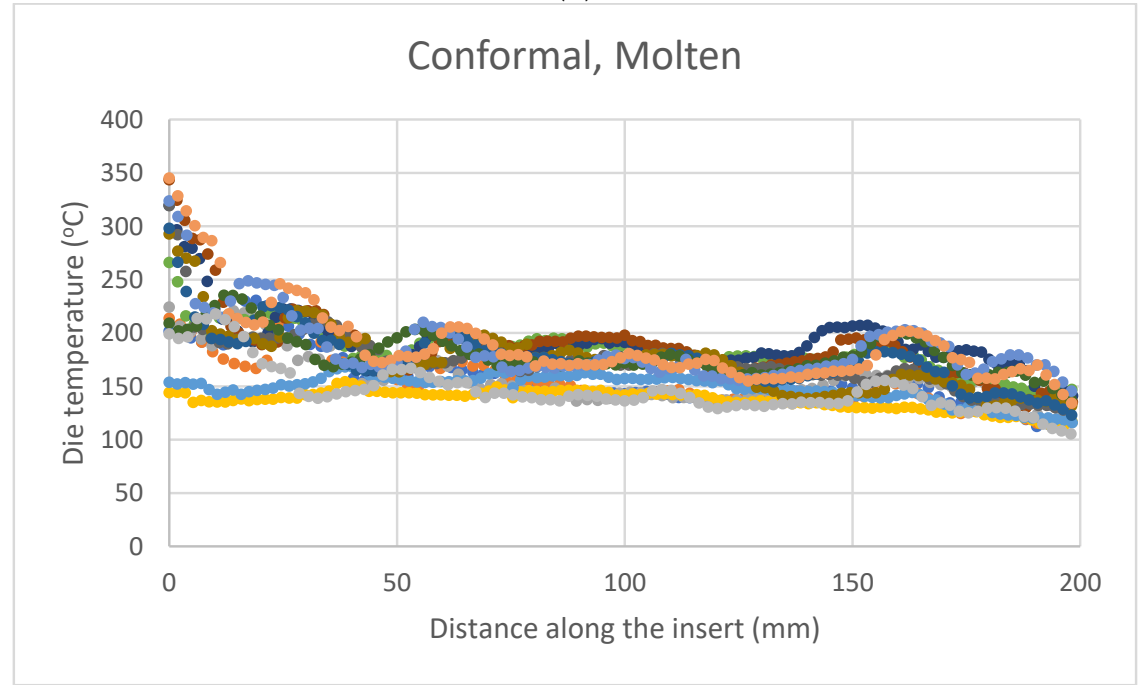

(c)

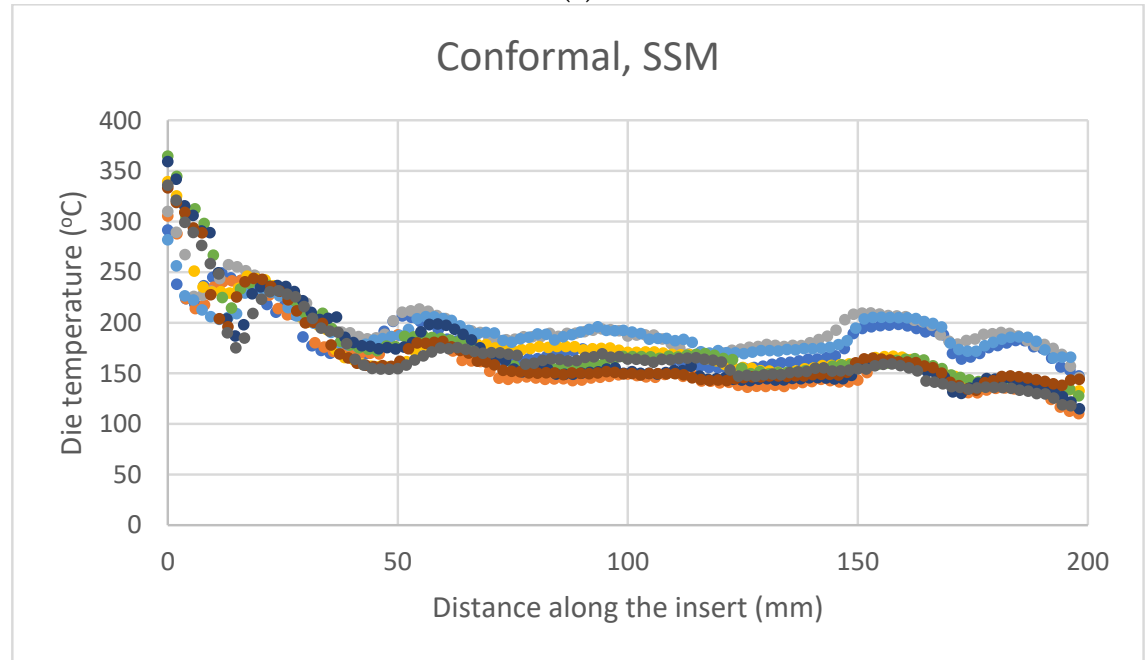

(d)

Figure 4. Illustration of temperature distributions in the upper moving die surface for (a) conventional die and a fully molten material; (b) conventional die with semisolid casting; (c) conformal die and a fully molten casting; and (d) conformal cooling and semisolid casting. 


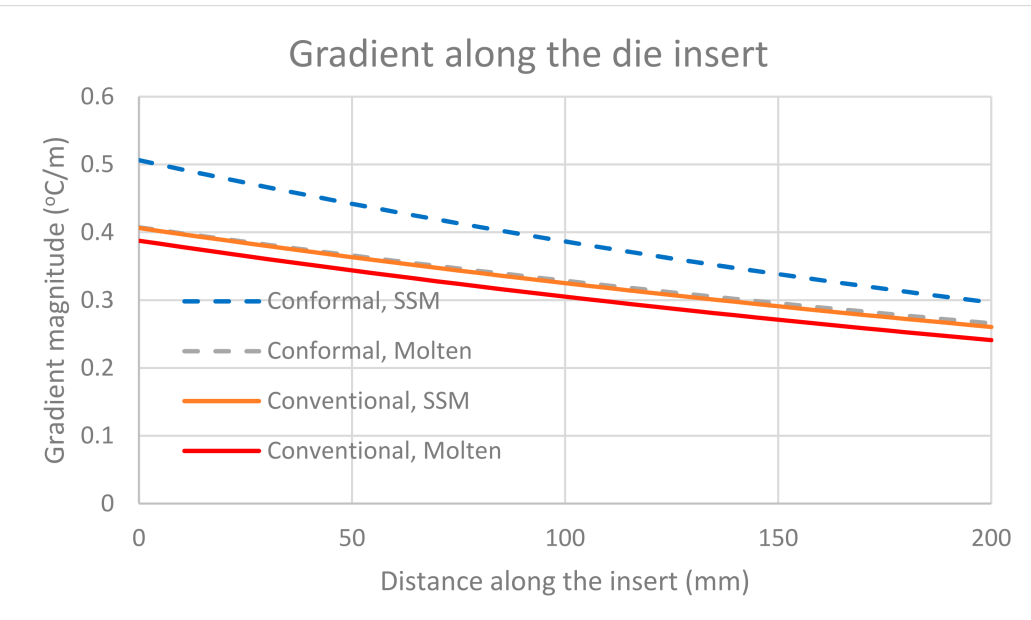

(a)

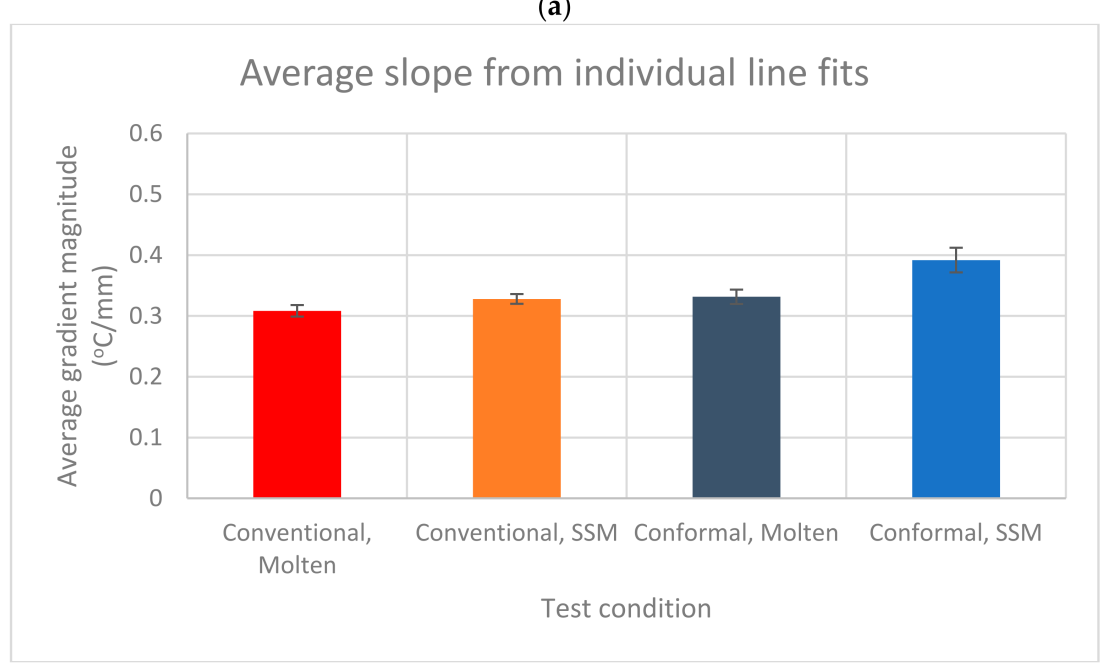

(b)

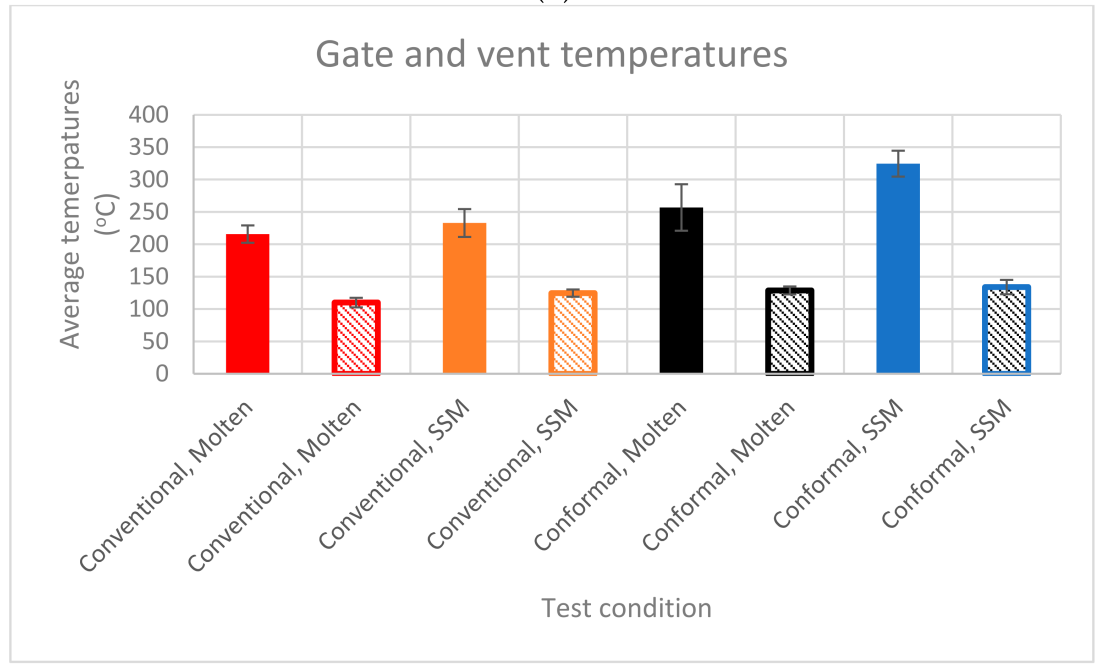

(c)

Figure 5. Analysis of temperature distributions for the different test conditions with (a) magnitude of the gradient for the different test cases; (b) overall average gradient and error for the four test cases; and (c) temperatures at the gate and the vent for the four different cases. The gate temperature is indicated as a solid bar, and the vent temperature is shown as a patterned bar. 
Interestingly, the increased cooling rate is of the same order of magnitude as for the semisolid cast material in the conventional die, Figure 5b. This effect was further accentuated for the rheocast material in the conformal cooling die, where the curve was shifted up with a significantly lower temperature effect in the die. For this case, the parts showed difficulties to fill, and thus the change in slope may be slightly affected by the short fill tendency.

Here, it should also be noted that the die temperature at the shot sleeve/biscuit location temperature varied significantly with the conformal cooling system and a semisolid casting reaching close to the Riemann temperature. On the other hand, the temperature at the vent did not vary significantly, Figure 5c.

The temperature distribution also affected the defect formation where porosity was found in the samples cast using the conformal cooling set-up, as shown in Figure 6. This porosity is located in the region indicated with grey in Figure 2c. Nine out of 25 investigated samples have this defect.

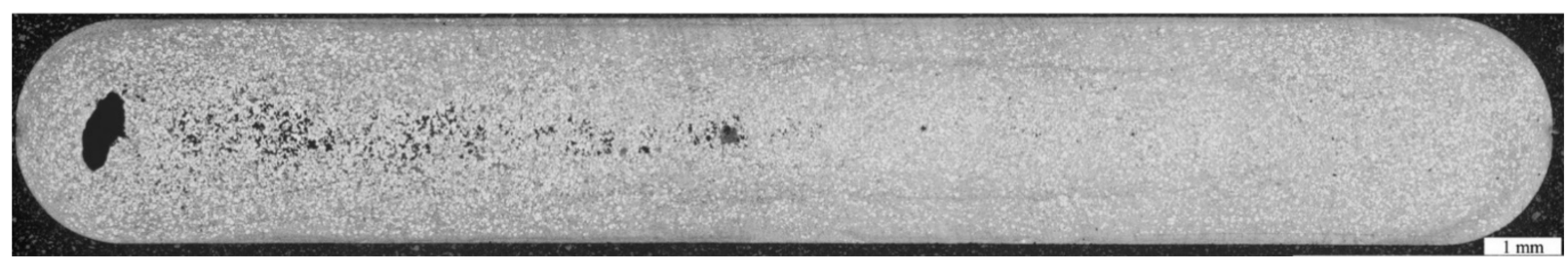

Figure 6. Cross-section perpendicular to filling direction. Filling defect located at the entry and exit point for the conformal cooling channel set-up indicated in Figure 2 with grey, corresponding to the left-hand side of the picture.

\section{Conclusions}

In the current study, the effects of conformal cooling were investigated by comparing temperature-time behaviour and temperature distribution analysis. The effect of a high and low heat transfer and heat load through the use of fully molten materials was investigated, and a semisolid material was used to achieve this. The conformal cooling loop was added before the conventional cooling system used for both cases, and the addition of the conformal loop was the only change.

The conformal cooling system was a channel designed along the die cavity with an inlet to the left of the metal in the filling direction, a counter flow on the left-hand side, and a flow along the casting on the filling direction on the right-hand side. The heat removal capacity was first analyzed through the oil flow and temperature change during the casting process. The analysis showed that the conformal system extracted three times as much heat from the die cavity as the conventional cooling solution. This supports the findings by Armilotta et al. [15] that recorded a reduced need for die spraying.

An analysis of the post-ejection cooling rate revealed that the initial cooling during the first $0.5 \mathrm{~s}$ revealed that the conformal cooling die showed a cooling rate that was eight times faster than the conventional die for fully molten metal. Reducing the heat input and decreasing the heat transfer coefficient using a semisolid metal displayed no difference in cooling rate between the conformal and conventional die. This suggests a relationship between the efficiency of the conformal cooling system and the heat transfer coefficient, where it is critical for a channel design to be effective. Further research and a different set of measurements are required to fully establish this.

One reason for using a conformal cooling channel is to change the temperature distribution, which was also investigated. The gradient along the die cavity immediately after part ejection was taken as a measure. The time for the analysis corresponds to approximately $1 \mathrm{~s}$ in the cooling cycle in Figure 2a. The main observation was that there was a tendency for the gradient to be more significant for the conformal cooling. The likely 
reason for this is that the conformal cooling die has a higher heat extraction and that the die surface at the time for the analysis is in a transient state since the time of analysis is just at the start of the cooling cycle.

It should also be noted that the temperature at the entrance was higher for semisolid material than for the fully molten material. Semisolid material requires a higher pressure at the entrance as its viscosity is higher. Koru and Serce [16] determine the pressure effect in HPDC processing for the heat transfer coefficient to be $0.030718 \mathrm{~kW} / \mathrm{m}^{2} \mathrm{~K}$ Bar. This is because the magnitude of the heat transfer coefficient started at $17 \mathrm{~kW} / \mathrm{m}^{2} \mathrm{~K}$ and the difference in temperature between the semisolid and fully molten conditions were $7 \%$ for the conventional and $26 \%$ for the conformal system. This suggests an inlet pressure ratio of at least 46 for the conventional die and 145 for the conformal die between the semisolid and fully liquid cases. This appears reasonable as the conformal die extracts heat more rapidly, and the semisolid material viscosity should increase more rapidly during filling, increasing contact pressures dramatically at the entrance and thereby also locally the interfacial heat transfer coefficient. Here it should also be noted that 9/25 samples displayed porosity for the semisolid casting at the grey area indicated in Figure 2c, suggesting significant issues with the filling for the conformal cooling die. Based on this, it will be challenging to improve component properties using conformal cooling, and the significant benefits in cycle-time, die-life, and thus, cost and productivity, should be prioritized.

The key takeaways from this study were that conformal cooling aids the die temperature reduction and may extend service life for inserts and die elements subjected to heat and at risk of thermal softening. This temperature reduction may also reduce the need for die spray.

In terms of filling, the increased temperature reduction may not be directly helpful in HPDC applications, and there appear to be no immediate effects of benefits for semisolid casting in the actual cavity. However, managing temperature around the inlet bushing and possibly the runner system appears to be an issue, especially for semisolid casting.

Author Contributions: Conceptualization, A.E.W.J. and R.S. (Ruslan Sevastopol); methodology, A.E.W.J., R.S. (Ruslan Sevastopol) and R.S. (Roland Stolt); formal analysis, A.E.W.J. and R.S. (Ruslan Sevastopol); investigation, R.S.(Ruslan Sevastopol), Q.Z., J.S. and R.S. (Roland Stolt); writingoriginal draft preparation, A.E.W.J. and R.S. (Ruslan Sevastopol); writing-review and editing, A.E.W.J., R.S. (Ruslan Sevastopol), K.S., Q.Z., J.S. and R.S. (Roland Stolt); supervision, A.E.W.J., K.S. and R.S. (Roland Stolt); project administration, A.E.W.J. and K.S.; funding acquisition, A.E.W.J. All authors have read and agreed to the published version of the manuscript.

Funding: Funding was received from Knowledge Foundation under the ToolAddict project contract number 20160327 and teaching funding at Jönköping University.

Institutional Review Board Statement: Not applicable.

Informed Consent Statement: Not applicable.

Data Availability Statement: The data presented in this study are available on request from the corresponding author. The data are not publicly available due to limitations in spreading to a third party in the project collaboration agreement.

Acknowledgments: The authors would like to express their gratitude for the materials and support provided by Uddeholm Tooling in the creation of the tool insert.

Conflicts of Interest: The authors declare no conflict of interest.

\section{References}

1. Sivertsen, H.S. Die Life Prediction Using High Pressure Die Casting Simulations. Master's Thesis, Jönköping University, Department of Materials and Manufacturing, Jönköping, Sweden, 2020.

2. Naimi, S.; Hosseini, S.M. Tool Steels in Die-Casting Utilization and Increased Mold Life. Adv. Mech. Eng. 2015, 7, 1-10. [CrossRef]

3. Kovács, S.E.; Varga, L.; Szentes, Z. Analysis of a Special, 3D Metal-Printed HPDC Tool Material. Int. J. Eng. Manag. Sci. 2020, 5, 251-265. [CrossRef] 
4. Vicario, I.; Idoiaga, J.K.; Arratibel, E.; Erauskin, I.; Plaza, L.M.; Crespo, I.; Caballero, P. Development of HPDC Advanced Dies by Casting with Reinforced Tool Steels. Int. J. Manuf. Eng. 2015, 2015, 1-10. [CrossRef]

5. Fiorentini, F.; Curcio, P.; Armentani, E.; Rosso, C.; Baldissera, P. Study of Two Alternative Cooling Systems of a Mold Insert Used in Die Casting Process of Light Alloy Components. Procedia Struct. Integr. 2019, 24, 569-582. [CrossRef]

6. Arisuda, Y.; Hasuno, A.; Yoshida, J.; Tanii, K. Improvement of Die Life in High Speed Injection Die Casting. China Foundry 2008, 5, 280-285.

7. Cao, Y.; Guo, Z.; Xiong, S. Determination of the Metal/Die Interfacial Heat Transfer Coefficient of High Pressure Die Cast B390 Alloy. Iop Conf. Ser. Mater. Sci. Eng. 2012, 33, 012010. [CrossRef]

8. Kuo, J.H.; Weng, R.J.; Hwang, W.S. Effects of Solid Fraction on the Heat Transfer Coefficient at the Casting/Mold Interface for Permanent Mold Casting of AZ91D Magnesium Alloy. Mater. Trans. 2006, 47, 2547-2554. [CrossRef]

9. Long, A.; Thornhill, D.; Armstrong, C.; Watson, D. Predicting Die Life from Die Temperature for High Pressure Dies Casting Aluminium Alloy. Appl. Therm. Eng. 2012, 44, 100-107. [CrossRef]

10. Stolt, R.; Elgh, F.; Jarfors, A. Challenges and Support When Introducing AM in HPDC Tooling. Adv. Transdiscipl. Eng. 2019, 10, 147-156. [CrossRef]

11. Sachs, E.; Wylonis, E.; Allen, S.; Cima, M.; Guo, H. Production of Injection Molding Tooling with Conformal Cooling Channels Using the Three Dimensional Printing Process. Polym. Eng. Sci. 2000, 40, 1232-1247. [CrossRef]

12. Jahan, S.A.; El-Mounayri, H. A Thermomechanical Analysis of Conformal Cooling Channels in 3D Printed Plastic Injection Molds. Appl. Sci. 2018, 8, 2567. [CrossRef]

13. Jarfors, A.E.W. Solidification Behaviour of AI-7\% Si-0.3\% Mg during Rotary Spray Forming. J. Mater. Sci. 1998, 33, 3907-3918. [CrossRef]

14. Granath, O.; Wessén, M.; Cao, H. Determining Effect of Slurry Process Parameters on Semisolid A356 Alloy Microstructures Produced by RheoMetal Process. Int. J. Cast Met. Res. 2008, 21, 349-356. [CrossRef]

15. Armillotta, A.; Baraggi, R.; Fasoli, S. SLM Tooling for Die Casting with Conformal Cooling Channels. Int. J. Adv. Manuf. Technol. 2014, 71, 573-583. [CrossRef]

16. Koru, M.; Serçe, O. Experimental and Numerical Determination of Casting-Mold Interfacial Heat Transfer Coefficient in the High Pressure Die Casting of A-360 Aluminum Alloy. Acta Phys. Pol. A 2016, 130, 453-458. [CrossRef] 